\title{
Amygdala lesions impair context aversions but not the ability of contexts to serve as occasion setters
}

\author{
DARLENE M. SKINNER, HANCE A. CLARKE, and DEREK VAN DER KOOY \\ University of Toronto, Toronto, Ontario, Canada
}

\begin{abstract}
Rats with large amygdala lesions (Experiment 1) were compared with sham controls on a conditional discrimination task that allowed assessment of occasion-setting learning. A saccharin solution was paired with lithium chloride in one context, but with saline in a second context. All the groups learned to suppress fluid consumption in the first, relative to the second, context. Sham lesioned rats, but not amygdala-lesioned rats, also showed a large aversion to the first context on a choice test. Shamlesioned Pavlovian control groups, given direct pairings of Context 1 with lithium chloride and of Context 2 with saline, showed large aversions to Context 1, whereas similarly trained amygdala-lesioned rats did not avoid the context associated with lithium chloride. Rats with discrete lesions of either the central nucleus or the basolateral nucleus (Experiment 2) of the amygdala were not impaired on the conditional discrimination task but did show deficits on the place choice test. The data from amygdalalesioned rats in the present study support previous behavioral data in suggesting that the aversive properties of contextual cues, as acquired through Pavlovian conditioning, are neither necessary nor sufficient for occasion-setting learning.
\end{abstract}

Amygdala lesions are known to impair performance on aversively motivated tasks, in which neutral stimuli are paired with stimuli that elicit avoidance (Davis, 1992; LeDoux, 1993). Pairing visual, auditory, or contextual cues with a mild footshock in rats results in significant freezing to each of these cues on subsequent presentations, and this conditioned freezing depends on the amygdala (Fanselow \& Kim, 1994; LeDoux, Cicchetti, Xagoraris, \& Romanski, 1990; Phillips \& LeDoux, 1992). In addition to the simple form of conditioning that is impaired by amygdala lesions, particularly where a conditioned stimulus (CS) is paired with an aversive unconditioned stimulus (US), there exists an independent type of learning, called occasion setting, where the significance of the CS depends on the prior occurrence of another conditional cue (Holland, 1989, 1991; Rescorla, 1991). In one theoretical account of occasion setting, the modulatory powers of a stimulus are thought to be independent of that cue's direct association with the US (Holland, 1989). The occasion setter modulates a CS-US association. At least two other accounts of occasion setting exist. One view postulates that, in an occasion-setting task, responding comes under the control of configural cues. That is, the compound cue of occasion setter and CS controls responding more than does either cue alone (Whitlow \& Wagner, 1972). Another account suggests that a cue can acquire motivational properties that can modulate

This work was supported by the Medical Research Council of Canada. Correspondence concerning this article should be addressed to D. M. Skinner, Department of Psychology, Memorial University of Newfoundland St. John's, NF A1B 3X9, Canada (e-mail: skinner@play. psych.mun.ca). other responses (Bombace, Brandon, \& Wagner, 1991). For example, conditioned fear to a context can potentiate an eyeblink response to another CS.

The conditional discrimination paradigm that we have used to sample occasion setting involves pairing a novel flavor with lithium chloride $(\mathrm{LiCl})$ in one distinct context and pairing the same flavor with saline in a second distinct context. Over the course of training, rats come to consume significantly less fluid in the first, relative to the second, context (Skinner, Martin, Harley, et al., 1994; Skinner, Martin, Pridgar, \& van der Kooy, 1994). We have previously shown that performance on this task is not due to a Pavlovian association between Context 1 and $\mathrm{LiCl}$ (Skinner, Martin, Harley, et al., 1994; Skinner, Martin, Pridgar, \& van der Kooy, 1994). Control rats given direct pairings of Context 1 with $\mathrm{LiCl}$ and of Context 2 with saline did not suppress fluid consumption in Context 1 but did, however, show significant avoidance of Context 1 on a place choice test (Skinner, Martin, Harley, et al., 1994; Skinner, Martin, Pridgar, \& van der Kooy, 1994). The conditional discrimination group also showed a significant aversion to Context 1 on a place choice test. Extinction tests revealed that the occasion setting function of contextual cues could be abolished, leaving intact the Pavlovian aversion (Skinner, Martin, Pridgar, \& van der Kooy, 1994), which suggests that a context-LiCl direct association is not sufficient to produce differential fluid consumption. These data would seem to argue against the explanation of occasion setting by conditioned motivation (Bombace et al., 1991). Furthermore, conditional control over fluid consumption transfers to another fluid, suggesting that performance is not due to learning about configural cues. If performance depended on a unique con- 
figural cue consisting of the occasion setter and a specific fluid, substituting a new fluid should disrupt performance. However, it remains possible that a configural cue of the context plus liquid (or drinking) controls performance on this conditional discrimination task, and so, no disruption on the transfer test would be expected. These transfer data do seem incompatible with Holland's view of occasion setting (Holland, 1989), where an occasion is thought to modulate a particular CS-US association. However, we have previously argued that, within the taste-aversion framework, contextual cues modulate a response-sickness association, rather than a CS-sickness association (Skinner, Martin, Pridgar, \& van der Kooy, 1994). The modulation of responses might not be surprising, if one considers that rats must make a response (drinking) to gain access to the target cue (saccharin). Evidence for the modulation of responses by conditional cues also exists in more traditional operant occasion-setting experiments (see Holland, 1995).

Given the role of the amygdala in aversive conditioning in rats, it is possible that acquisition of our aversively motivated, conditional discrimination task will be impaired in amygdala-lesioned rats. Examining the performance of amygdala-lesioned rats on a conditional discrimination task may also provide insights into the nature of the associations formed in this type of task. It is possible that amygdala lesions will disrupt the direct association between the context and the US, as is seen in context fear-conditioning studies. We have previously argued, primarily on the basis of behavioral data, that the modulatory properties of contexts are independent of their direct associations with the US. If amygdala lesions do disrupt context-US associations, we can determine the extent to which conditional discrimination learning depends on simple conditioning to the context. In Experiment 1, we compared rats with large lesions of the entire amygdala with sham-lesioned rats on the conditional discrimination task. Encouraged by the findings from this experiment, we proceeded to lesion discrete amygdala nucleinamely, the central nucleus and the basolateral nucleus (Experiment 2)-and to look at performance on the same conditional discrimination task. There is currently some debate as to whether information within the amygdala is processed in a parallel or a serial manner (Killcross, Robbins, \& Everitt, 1997; Nader \& LeDoux, 1997). Since the large amygdala lesions in Experiment 1 produced a deficit on the place test, our measure of Pavlovian conditioning to the context, we attempted to localize this deficit in Experiment 2 and, perhaps, provide some insight into the current debate of how information is processed within the amygdala.

\section{EXPERIMENT 1}

Amygdala- and sham-lesioned rats were trained on a conditional discrimination, with one set of contextual cues signaling a saccharin- $\mathrm{LiCl}$ pairing and a second set of contextual cues signaling a saccharin-vehicle pairing.
Separate groups of amygdala- and sham-lesioned rats were given Pavlovian pairings of one context with $\mathrm{LiCl}$ and of a second context with saline. This control procedure was used because the most obvious solution to the conditional discrimination task is for the rat to form direct associations between Context 1 and $\mathrm{LiCl}$ and between Context 2 and saline. Saccharin is only a $50 \%$ predictor of $\mathrm{LiCl}$. This conditional discrimination task has a taste-aversion component, and several studies have suggested that amygdala lesions impair conditioned taste aversions (CTAs) (Gallo, Roldan, \& Bures, 1992; Gaston, 1978; Kesner, Berman, Burton, \& Hankins, 1975; Kesner, Berman, \& Tardif, 1992). However, it has been suggested that CTAs are only impaired if there is damage to the fibers of passage (Dunn \& Everitt, 1988). If amygdala lesions disrupt CTAs, we would expect to see no evidence of differential consumption; rats should consume large amounts of fluid in both contexts. We tested the effects of amygdala lesions on taste-aversion learning directly by looking at acquisition of a CTA in different groups of amygdalaand sham-lesioned rats.

\section{Method}

Subjects. Forty-three adult male Wistar rats (Charles River, Quebec), weighing 350-400 $\mathrm{g}$ at the beginning of behavioral training, were used as subjects. All the rats underwent surgery within 1 or 2 weeks of their arrival in the laboratory. After recovery from surgery, the rats were adapted to a water deprivation schedule consisting of 60 -min access to tap water each afternoon. One week later, behavioral training began.

Surgery. Twenty-one rats underwent ibotenic acid lesions of the amygdala. The rats were anesthetized with sodium pentobarbital $(65 \mathrm{mg} / \mathrm{kg}$ intraperitoneally [i.p.]) and placed in a stereotaxic instrument. After a scalp incision was made, holes were drilled in the skull to permit microinjections of the ibotenic acid (Sigma Chemicals, St. Louis). By using a 1.0- $\mu$ l Hamilton syringe mounted on the stereotaxic instrument, injections of $2 \%$ ibotenic acid were made at each of two sites, one site per hemisphere (AP - 2.3; ML \pm 4.6 ; DV from dura -7.4$)$ in a volume of $0.5 \mu \mathrm{l} / \mathrm{site}$. Ibotenic acid was injected at a rate of $0.05 \mu \mathrm{l} / \mathrm{min}$, and the needle was left in place for an additional $5 \mathrm{~min}$ following infusion. Twenty-two sham-lesioned rats were treated in the same manner but were injected with sterile saline $(0.9 \% \mathrm{NaCl})$.

Conditional discrimination and Pavlovian training. After recovery from surgery, two groups of rats $(n=7$, sham-lesioned [SDIS], and $n=7$, amygdala-lesioned [A-DIS] rats) were trained on a conditional discrimination task, similar to that used previously (Skinner, Martin, Harley, et al., 1994; Skinner, Martin, Pridgar, \& van der Kooy, 1994). This phase of the experiment was divided into danger and safe days. On danger days, the rats were placed in a novel context $15 \mathrm{~min}$ prior to 15 -min access to a novel $0.1 \%$ saccharin (Sigma Chemicals, St. Louis) solution. Removal of the saccharin solution was followed by an i.p. injection of $60 \mathrm{mg} / \mathrm{kg} \mathrm{LiCl}$ (Sigma Chemicals, St. Louis) dissolved in $3 \mathrm{ml} / \mathrm{kg}$ physiological saline, and the rats were returned to the home cage. On safe days, the rats were placed in a second novel context $15 \mathrm{~min}$ prior to 15 -min access to the same saccharin solution. Saccharin removal was followed by an i.p. injection of physiological saline, and the rats were returned to the home cage. The training contexts were wooden boxes measuring $41 \times 41 \times 38 \mathrm{~cm}$. For half the rats, the danger context was a black box with a Plexiglas floor wiped with $2 \%$ acetic acid solution prior to each trial. The safe context was a white box with a wire-mesh floor covered with wood chips. The other half of the rats had these contextual cues reversed. 
Two additional groups of rats ( $n=7$, sham-lesioned [S-CON], and $n=6$, amygdala-lesioned [A-CON] rats) were trained on a simple Pavlovian control task. On danger days, all the rats were placed in a novel context for $30 \mathrm{~min}$ (to equate exposure in the Pavlovian and the conditional discrimination groups), followed by an i.p. injection of $\mathrm{LiCl}$, and then were returned to the home cage. On safe days, the rats were exposed to a second novel context for $30 \mathrm{~min}$, followed by an i.p. injection of saline. The contextual cues were the same as those described above. These rats were given 15-min access to the saccharin solution each day, approximately $3 \mathrm{~h}$ after training, in the home cage in order to equate exposure to all the elements in all the groups.

This phase of the experiment consisted of 18 cycles of alternating safe and danger days for all four groups (two conditional discrimination groups and two Pavlovian control groups). This pattern of alternating days of $\mathrm{LiCl}$ and saline injections is not sufficient to produce discriminative performance in the absence of a conditional cue (see Skinner, Martin, Howe, Pridgar, \& van der Kooy, 1995). In addition, switching the pattern of days in trained animals from an alternating sequence to one in which several successive safe (or danger) days are given does not disrupt performance. At the end of discrimination training, all the rats were given a 2-day transfer test with a novel $2 \%$ vinegar solution. This transfer test was used to determine whether the rats were learning about a compound cue of the context and saccharin. If the rats were learning about a compound cue, disrupting this cue by the presentation of another fluid should have disrupted performance. The rats were exposed to both training contexts, in a counterbalanced order, $15 \mathrm{~min}$ prior to 15 min access to the vinegar solution. No injections were given after removal of the flavored solution. For the rats in the two Pavlovian control groups, the vinegar transfer test was the first time fluids were given in the training contexts.

Place aversion testing. Throughout the discrimination training phase, the rats were given five place tests, one after each of Cycles $2,6,10,14$, and 18 , to assess acquisition of a Pavlovian aversion to the context associated with $\mathrm{LiCl}$ in all the groups. The test procedure consisted of placing a rat in a neutral gray zone between the black and the white contexts used during training. The amount of time spent in each of the two training contexts was recorded in seconds for a 10-min period. The presence of the neutral gray zone meant that time spent in the danger context was independent of time spent in the safe context. Since the contextual cues were counterbalanced (half the rats had the black box as the $\mathrm{LiCl}$-paired context, and half had the black box as the saline-paired context), we did not measure the initial preferences of the individual rats prior to training. However, considerable previous work using identical contextual cues has shown that naive rats, on average, show a 50:50 split of their time in the two contexts on a place choice test (Bechara \& van der Kooy, 1992; Mucha, van der Kooy, O'Shaughnessy, \& Bucenieks, 1982)

Conditioned taste-aversion acquisition. An additional group of amygdala $(n=8)$ and sham $(n=8)$ lesioned rats were trained on a conditioned taste aversion. During this phase of the experiment, all the rats were given four pairings of a novel saccharin solution with $\mathrm{LiCl}$ (all concentrations and doses were the same as those in the previous groups). The saccharin bottle was presented to the animals in the home cage for a 15-min period, after which the bottle was removed and the rats were injected with $\mathrm{LiCl}$. On the day preceding each saccharin trial, all the rats were given tap water for $15 \mathrm{~min}$, followed by an injection of physiological saline. For the purpose of statistical analysis, saccharin consumption was expressed as a percentage of tap water consumption from the previous day. On the day following completion of the acquisition phase, all the rats were given a two-bottle choice test with saccharin and tap water in the home cage for a 15 -min period.

Histology. After completion of behavioral experiments, all the rats were deeply anesthetized with sodium pentobarbital and perfused through the heart with isotonic saline, followed by $10 \%$ for- malin. The brains were removed and stored in $25 \%$ sucrose, and then $30 \mu$ cryostat sections were cut. Sections were mounted on slides and stained with cresyl violet, in order to verify the placement and extent of the lesions.

\section{Results and Discussion}

Histology. All of the lesioned rats had extensive damage to the amygdala. The majority of the rats had nearcomplete ablation of the central, lateral, basolateral, and basomedial nuclei of the amygdala. Most rats had some extra-amygdala damage, including the most ventral portion of the caudate-putamen, the piriform cortex, and the dorsal and ventral endopiriform nuclei. Although ibotenic acid usually spares fibers of passage, the lesioned rats in this experiment had cavities at the injection site that obviously disrupted some fibers of passage. Such cavities may be the consequence of the long interval between surgery and histology (Brown \& Fibiger, 1993), which, in the present case, was approximately 3 months. The rats injected with saline showed some enlargement of the inferior horn of the lateral ventricle but little or no damage to the amygdala. In some cases, there was blood along the needle track. Figure 1 is a schematic showing the largest and smallest amygdala lesions.

Conditional discrimination training. Rats with large bilateral lesions of the amygdala and sham-lesioned controls acquired the occasion-setting function of contextual cues. Any difference between the two groups could be accounted for by nonassociative effects (see below). Both the A-DIS and the S-DIS groups learned to sup-

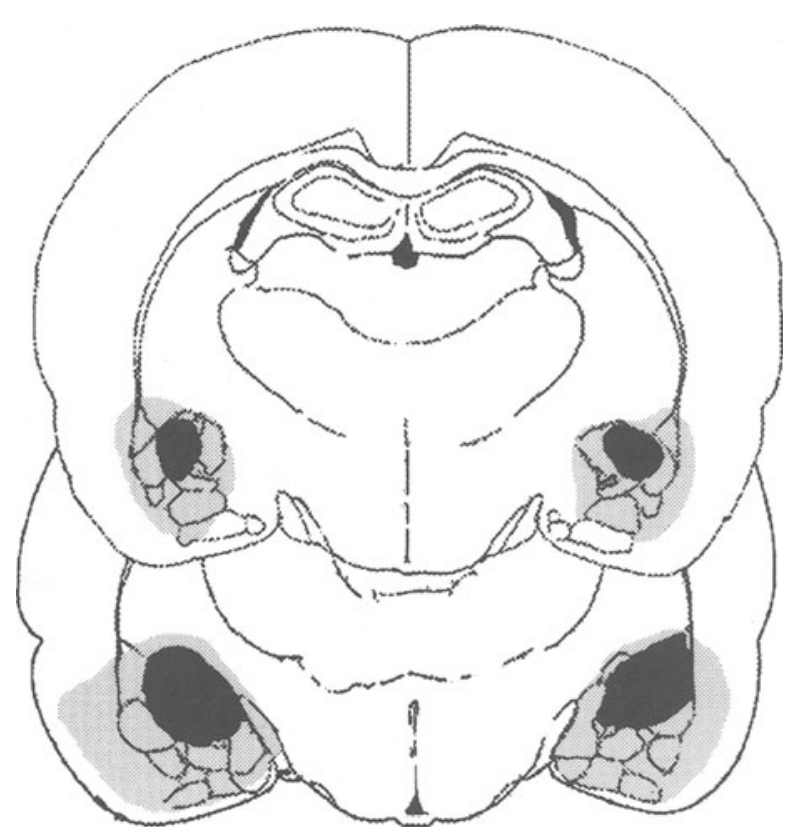

Figure 1. Schematic drawings of two coronal sections (AP from bregma -2.12 and 2.60) of the largest (gray) and smallest (black) amygdala lesions in the rats from Experiment 1. From The Rat Brain in Stereotaxic Coordinates (Figures 26 and 28), by G. Paxinos and C. Watson, 1982, New York: Academic Press. Copyright 1982 by Academic Press. Adapted with permission. 


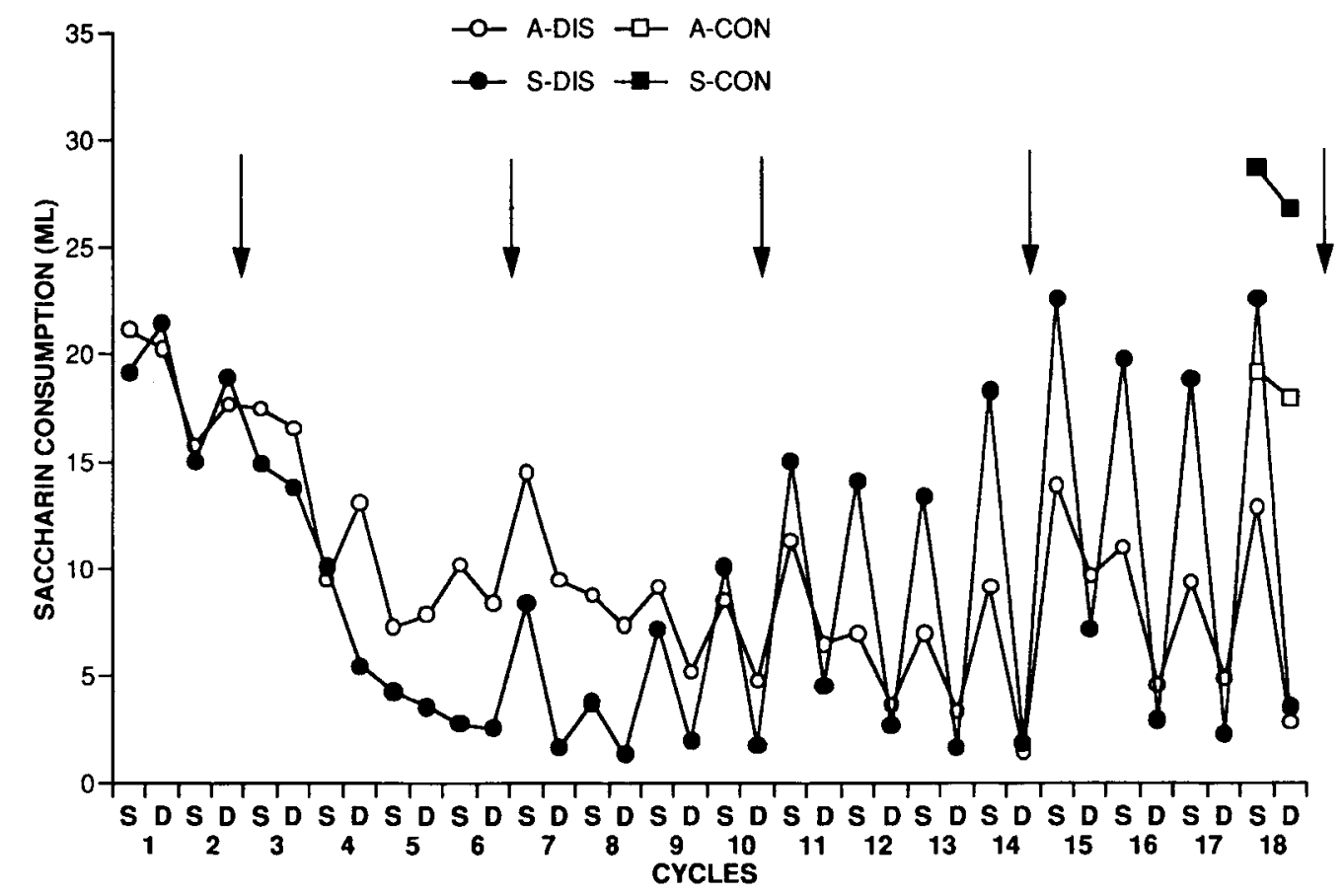

Figure 2. Saccharin consumption (in milliliters) by the sham- $(n=7)$ and amygdala- $(n=7)$ lesioned conditional discrimination groups (S-DIS and A-DIS, respectively) during the 18 cycles of conditional discrimination training in Experiment $1 . S$ = safe day trials, where the rats received Context 1 paired with saccharinsaline; $D=$ danger day trials, where the rats received Context 2 paired with saccharin-LiCl. Saccharin consumption in the home cage by the two Pavlovian control groups (S-CON and A-CON) is shown for the last 2 days of training. Arrows indicate when the place tests were performed.

press saccharin consumption in the danger context, relative to the safe context, over the 18 cycles of training, with differential consumption emerging around Cycle 7 in both groups (Figure 2 ). A $2 \times 18 \times 2$ (groups $\times$ cycles $\times$ trials) analysis of variance (ANOVA) over the entire phase revealed a significant three-way interaction $[F(17,216)=3.51, p<.05]$, reflecting the lower levels of saccharin consumption by amygdala-lesioned rats, as compared with sham-lesioned rats, on safe trials. A $2 \times$ 2 (groups $\times$ trials) ANOVA over the last cycle of training revealed a significant two-way interaction $[F(1,12)=$ $10.15, p<.05]$. A follow-up Newman-Keuls test revealed that both the A-DIS and the S-DIS groups consumed significantly less saccharin on the danger trial, relative to the safe trial $(p s<.05)$. The two groups consumed equal amounts on the danger trial $(p>.05)$, but the S-DIS group consumed significantly more saccharin than did the A-DIS group on the safe trial $(p<.05)$.

The two Pavlovian control groups (S-CON and A-CON) consumed large amounts of the saccharin solution on both trials of each cycle throughout training. This is not surprising given that saccharin was given in the home cage 3 hours after training. On the last cycle (Figure 2), there was no significant difference between safe and danger day consumption in either of the groups. A $2 \times$ 2 (groups $\times$ trials) ANOVA over the last cycle revealed only a main effect of groups $[F(1,11)=17.42, p<.05]$, indicating that the amygdala-lesioned animals consumed less than the sham-lesioned animals. This difference in fluid consumption between the two Pavlovian control groups (difference of $8-10 \mathrm{ml}$ on the last 2 days of training) may explain the nature of the deficit of the amygdalalesioned rats trained on the conditional discrimination task. Saccharin consumption was comparable between the A-DIS and the S-DIS groups in the danger context, but consumption was lower in the amygdala-lesioned rats in the safe context. The magnitude of difference in consumption between these two groups on safe trials (approximately $10 \mathrm{ml}$ on the last cycle) was the similar to the difference between the A-CON and the S-CON groups. Thus, the poorer performance of the A-DIS group on the conditional discrimination task may not reflect an impairment of occasion setting but, rather, a nonassociative deficit in consummatory responding (since a similar effect was seen in the A-CON group, where saccharin was never paired with $\mathrm{LiCl}$ ). Indeed, both the A-DIS and the S-DIS groups start to show differential fluid consumption around the same time (Cycle 7), but the differential was bigger in the sham-lesioned rats. Thus, amygdalalesioned rats drank less saccharin than sham-lesioned rats, regardless of context (novel or home cage) and whether or not saccharin had been paired with $\mathrm{LiCl}$. This difference between amygdala- and sham-lesioned rats on saccharin consumption emerges over time. Saccharin consumption was equivalent in the two conditional discrimination groups initially (see Figure 2). Saccharin consumption 
was equivalent in the two Pavlovian control groups on the first trial as well (amygdala $=20.3 \mathrm{ml}$ and sham $=20.7 \mathrm{ml}$; data not shown). Thus, this deficit probably reflects some nonassociative effect of $\mathrm{LiCl}$ exposure in amygdalalesioned rats that develops with repeated injections.

If the deficit seen in the amygdala-lesioned rats was a true occasion-setting impairment--that is, the rats could not use the conditional cues to predict when the saccharin would be followed by a $\mathrm{LiCl}$ injection-we would have expected the rats to consume the same low amount in both training contexts. Previous behavioral work has demonstrated that rats given the same pattern of alternating $\mathrm{LiCl}$ and saline injections but no informative conditional cue develop an overall taste aversion (Skinner et al., 1995). This did not happen in the present experiment. The amygdala-lesioned rats did show differential fluid consumption in the two contexts that emerged at the same time as the differential fluid consumption in shamlesioned rats.

The transfer test with the novel vinegar flavor revealed a pattern typical of that reported previously (Skinner, Martin, Harley, et al., 1994; Skinner, Martin, Pridgar, \& van der Kooy, 1994), where rats trained on a conditional discrimination to avoid saccharin in one context also showed suppression of other fluids in that same context. Although performance on the transfer test was not as good as that with the original saccharin target, both the A-DIS and the S-DIS groups suppressed consumption in the danger context, relative to the safe context (Figure 4A). Since exposure to the contexts was counterbalanced during this test, the rats were probably not solving the conditional discrimination on the basis of the pattern of alternating safe and danger days. A $2 \times 2$ (groups $\times$ trials) ANOVA revealed only a significant main effect of trials $[F(1,12)=6.93, p<.05]$. Conversely, neither of the two Pavlovian control groups showed significant suppression of fluid consumption in the danger context, relative to the safe context. A $2 \times 2$ (groups $\times$ trials) ANOVA revealed no significant effects $(F \mathrm{~s}<1)$. Although it appears that the control groups suppressed consumption of vinegar in both contexts, we suggest that this is not the case, since consumption of vinegar in the danger context is higher than saccharin consumption by the discrimination groups in the danger context during initial training. These transfer data suggest that, during conditional discrimination training, rats are not forming a compound cue of the context plus saccharin, but also that the fluid suppression in the danger context is not a result of a direct context- $\mathrm{LiCl}$ association. The transfer data also support our contention that the contexts are modulating a drinking response. However, it is not possible to distinguish between this explanation and generalization based on some sensory properties common to all fluids. We note that rats consumed less of the vinegar solution than of the sweet saccharin solution (only about $10-12 \mathrm{ml}$ of vinegar in the safe context vs. 15-25 ml of saccharin), and the difference between the amygdala- and the shamlesioned rats on consumption was not apparent on the transfer test. Thus, the difference between amygdala- and sham-lesioned rats is not seen with the low baseline consumption on the vinegar test.

Place aversions. Amygdala lesions block simple Pavlovian conditioning to contextual cues. The place choice test was used as a measure of the simple Pavlovian aversion to the context that was associated with $\mathrm{LiCl}$ (Skinner, Martin, Harley, et al., 1994; Skinner, Martin, Pridgar, \& van der Kooy, 1994). As was stated in the Method section, the contextual cues were counterbalanced in each group, and so any preferences or aversions observed should reflect conditioning and not a natural bias for one environment over the other. Amygdala-lesioned rats trained on the Pavlovian task did not acquire a direct association between context and $\mathrm{LiCl}$, as was evidenced by a lack of avoidance on a place choice test, even after 18 pairings of context and $\mathrm{LiCl}$. In addition, the amygdala-lesioned group that acquired the occasion-setting function of contextual cues did not develop a significant Pavlovian aversion to the context that predicted $\mathrm{LiCl}$, as was seen in sham-lesioned rats.

The first of the place tests was given after Cycle 2 of discrimination training, before any evidence of discrimination learning was seen in the A-DIS and S-DIS groups (see Figure 2). While it appears that the S-DIS and S-CON groups showed an aversion to the context associated with $\mathrm{LiCl}$ and that the A-DIS and A-CON groups did not (Figure $3 \mathrm{~A}$ ), a $4 \times 2$ (groups $\times$ contexts) ANOVA revealed that the two-way interaction was not significant $[F(3,23)=$ $2.67, p=.071]$. However, a $2 \times 2$ (groups $\times$ contexts) ANOVA comparing only the S-DIS and the S-CON groups revealed a significant main effect of contexts only $[F(1,12)=9.78, p<.05]$. Conversely, a similar analysis comparing the A-DIS and the A-CON groups revealed no significant effects $(F \mathrm{~S}<1)$.

The second place test (Figure 3B) was completed after Cycle 6, when the S-DIS and A-DIS rats were still not showing any evidence of conditional discrimination learning. A $4 \times 2$ (groups $\times$ contexts) ANOVA revealed a significant two-way interaction $[F(3,23)=8.81, p<.05]$. Newman-Keuls tests revealed that the S-DIS and S-CON groups showed a significant aversion to the $\mathrm{LiCl}$-associated context $(p \mathrm{~s}<.05$ ), whereas the A-DIS and A-CON groups did not avoid the context associated with $\mathrm{LiCl}(p \mathrm{~s}>.05)$.

The third place test was completed after Cycle 10, when the rats in the two discrimination groups showed evidence of conditional discrimination learning. A $4 \times 2$ ANOVA again revealed a significant two-way interaction $[F(3,23)=$ $3.76, p<.05]$. Newman $-K e u l s$ tests revealed that the S-DIS and S-CON groups showed a significant aversion to the $\mathrm{LiCl}$-associated context ( $p \mathrm{~s}<.05$ ), whereas the A-DIS and A-CON groups did not avoid the context associated with $\mathrm{LiCl}(p \mathrm{~s}>.05$; Figure 3C). Although the A-DIS group showed a numerical difference between time spent in the danger context and time spent in the safe context, this difference did not reach statistical significance $[t(6)=1.7, p=.14]$. The A-CON group showed no evidence of an aversion to the danger context.

The fourth place test was performed after Cycle 14, when the S-DIS and A-DIS rats again showed evidence 

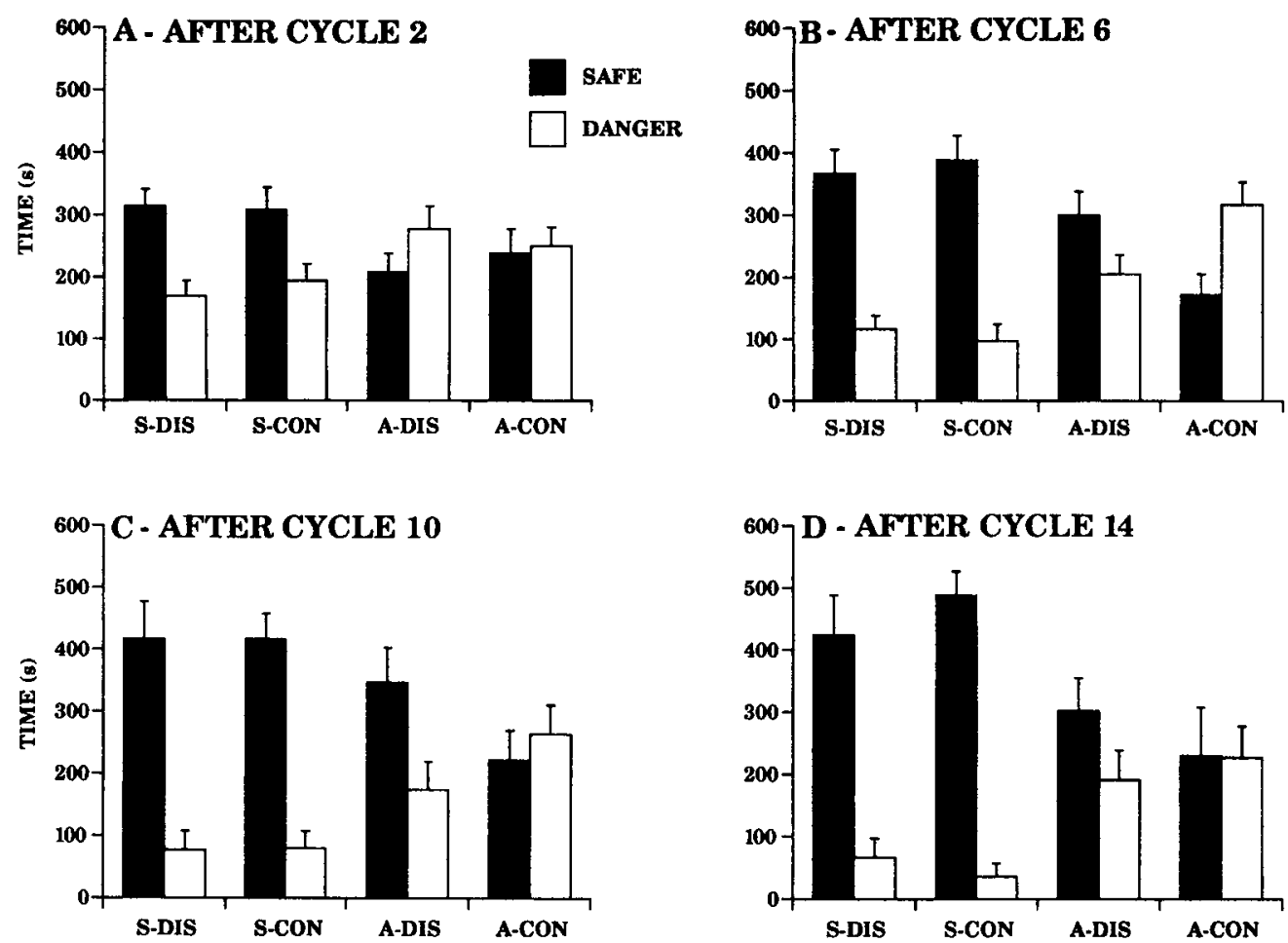

Figure 3. Panels $A, B, C$, and $D$ show performance on the first four place tests (after Cycles 2, 6, 10, and 14 , respectively) of Experiment 1 . Data represent the means $( \pm S E M)$ for times (in seconds) spent in each of the two training contexts during the 10-min place test by the rats in each of the four groups. S-DIS and S-CON represent sham-lesioned groups trained on the conditional discrimination and the Pavlovian control tasks, respectively. Similarly, A-DIS and A-CON represent amygdala-lesioned groups trained on the discrimination and control tasks. Safe $=$ the context associated with saline during training, and Danger $=$ the context associated with $\mathrm{LiCl}$ during training.

of conditional discrimination learning. As before, a $4 \times$ 2 ANOVA revealed a significant groups $x$ contexts interaction $[F(3,23)=4.89, p<.05]$. Newman Keuls tests revealed that the S-DIS and S-CON groups showed a significant aversion to the $\mathrm{LiCl}$-associated context $(p s<.05$ ), whereas the A-DIS and A-CON groups did not avoid the context associated with $\mathrm{LiCl}(p \mathrm{~s}>.05)$ (Figure 3D).

The final place test (Figure 4B) was conducted after 18 cycles of discrimination training and the vinegar transfer test and yielded results similar to the previous four place tests. The S-DIS and S-CON groups showed large aversions to the context associated with $\mathrm{LiCl}$. Although there was a hint of an aversion in the A-DIS group, it was not as large as the aversion in the S-DIS or the S-CON group, and there was not even a hint of an aversion in the A-CON group. Statistical analysis confirmed this overview. A $4 \times 2$ (groups $\times$ contexts) ANOVA revealed a significant two-way interaction $[F(3,23)=3.76, p<.05]$. Newman-Keuls tests revealed that the S-DIS and S-CON groups showed a significant aversion to the $\mathrm{LiCl}$-associated context $(p s<.05)$, whereas the A-DIS and A-CON groups did not avoid the context associated with $\mathrm{LiCl}$ $(p \mathrm{~s}>.05)$. Once again, the numerical difference between time spent in the two contexts in the A-DIS group did not reach statistical significance $[t(6)=1.3, p=0.26]$.
Indeed, there was no difference between the two amygdalalesioned groups. A $2 \times 2$ (groups $\times$ contexts) ANOVA comparing only the two amygdala-lesioned groups revealed no significant effects [largest $F(1,11)=1.49, p=$ $.25]$. Thus, although one may take the trend toward an aversion in the A-DIS group as evidence for a taste-mediated context aversion (Best, Brown, \& Sowell, 1984), the difference between the two amygdala groups was never statistically significant. In addition, this putative potentiated context aversion in the conditional discrimination group was not seen in sham-lesioned rats. The S-DIS and S-CON groups always showed equivalent context aversions on the place test. Thus, amygdala-lesioned rats, unlike sham controls, acquired the conditional discrimination task without ever showing a significant place aversion.

Conditioned taste-aversion learning. Although both sham- and amygdala-lesioned rats acquired a CTA within the four trials given, the amygdala rats were slower (Figure 5). Thus, amygdala-lesioned rats were impaired on two simple conditioning tasks, one that involved a place response and one that involved a taste response. A $2 \times 4$ (groups $\times$ trials) ANOVA over acquisition of the CTA revealed a significant two-way interaction $[F(3,56)=$ $5.37, p<.05]$. Newman-Keuls follow-up tests revealed that the amygdala group consumed more saccharin than 

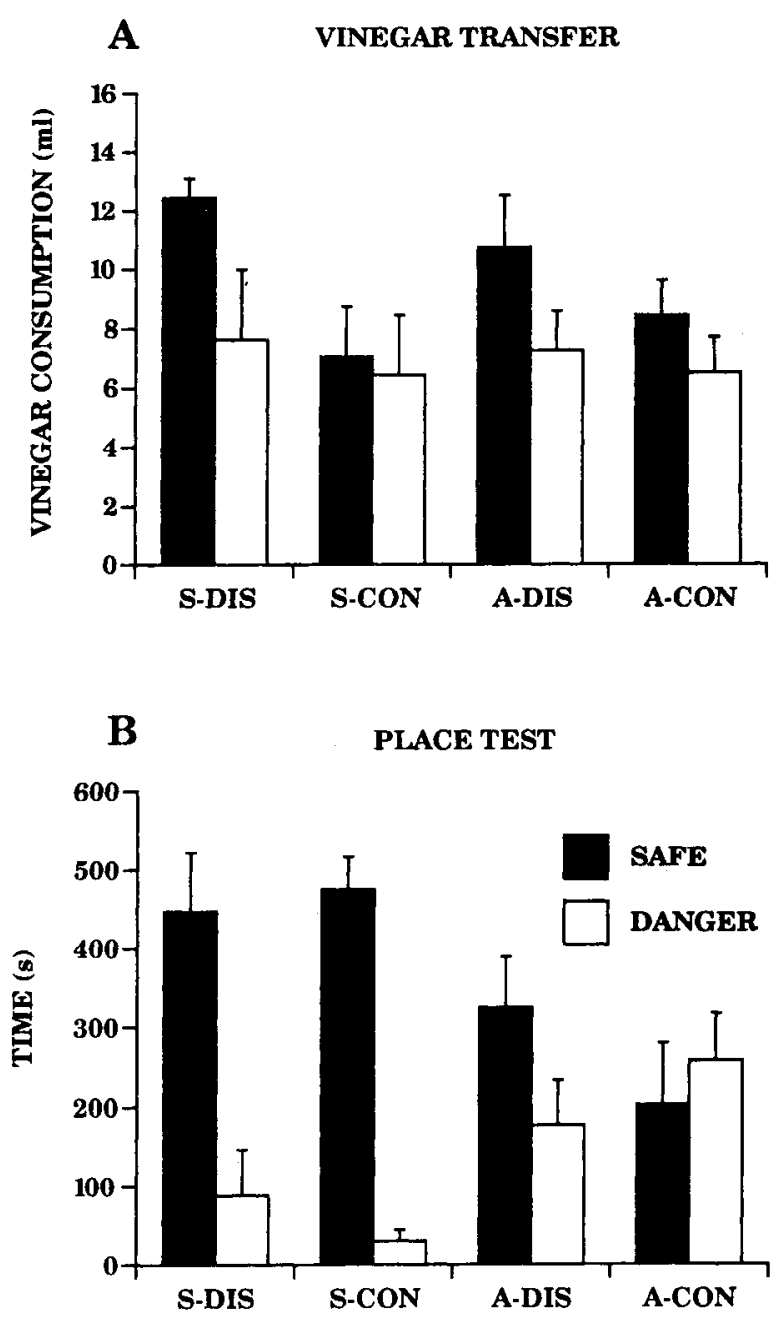

Figure 4. Panel A shows the means ( $\pm S E M$ ) for vinegar consumption (in milliliters) by the four groups in Experiment 1 during the 2-day transfer test. Panel B shows the means $( \pm S E M)$ for times (in seconds) spent in each of the two training contexts during the fifth and final $10-\mathrm{min}$ place test by the rats in the same four groups. S-DIS and S-CON represent sham-lesioned groups trained on the conditional discrimination and the Pavlovian control tasks, respectively. Similarly, A-DIS and A-CON represent amygdala-lesioned groups trained on the conditional discrimination and Pavlovian control tasks. Safe $=$ the context associated with saline during training, and Danger $=$ the context associated with $\mathrm{LiCl}$ during training.

did sham animals on the second trial $(p<.05)$ but that the two groups consumed similar amounts on all other trials $(p \mathrm{~s}>.05)$. The two groups did not differ on the two-bottle choice test (data not shown). A $2 \times 2$ (groups $x$ flavors) ANOVA revealed only a significant main effect of flavor $[F(1,14)=42.73, p<.05]$, confirming that both groups consumed less saccharin than tap water. These deficits in CTA learning could account for the finding that the amygdala-lesioned rats in the A-DIS group consumed slightly more saccharin than did sham.animals on Cycles 3-8 (see Figure 2). However, these effects on CTA acquisition were small and are not the reason for the poorer performance of the amygdala-lesioned rats dur- ing later cycles of the conditional discrimination task. In that task, the amygdala- and sham-lesioned rats consumed an equivalent and low amount of saccharin on danger trials from Cycle 11 to the end of training (see Figure 2). The difference between the two groups was most evident on safe trials.

\section{EXPERIMENT 2}

Experiment 1 demonstrated that rats with large lesions of the amygdala were impaired in the acquisition of a Pavlovian association between contextual cues and $\mathrm{LiCl}$. These data support a large body of research indicating that the neural system underlying emotional memory critically involves the amygdala. The amygdala can be divided into several subregions, or nuclei, with the central nucleus $(\mathrm{CN})$ and the basolateral nucleus $(\mathrm{ABL})$ receiving the most attention. One widely held belief is that the flow of information within the amygdala is a serial process (Nader \& LeDoux, 1997), with the ABL being the sensory interface that sends information to the $\mathrm{CN}$, which serves as the output nucleus for the expression of classically conditioned defensive responses. This serial-processing view has recently been called into question by findings demonstrating that these two nuclei have separate and dissociable roles in fear learning (Killcross et al., 1997). The $\mathrm{CN}$ was suggested to mediate the classical fear responses, whereas the ABL mediates the ability of a cue that has been associated with a dangerous event to influence ongoing behavior (Killcross et al., 1997).

Given the effects of large amygdala lesions (Experiment 1), we decided to do discrete lesions of the $\mathrm{CN}$ and $\mathrm{ABL}$. If information flows in a serial pathway within the amygdala, either lesion alone should produce the Pavlovian impairment seen in the last experiment. If parallel processing of information occurs in the amygdala, either structure alone should be able to support conditioning in

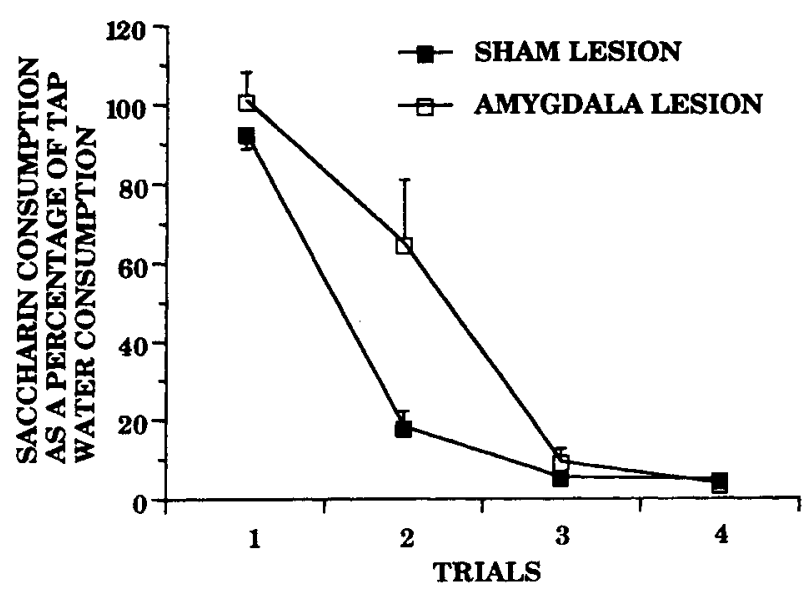

Figure 5. Consumption of saccharin expressed as a percentage of the previous day's tap water consumption (in milliliters) over four trials of conditioned taste-aversion acquisition for amygdala- $(n=8)$ and sham- $(n=8)$ lesioned rats in Experiment 1. Data represent the means $( \pm S E M)$. 
the absence of the other. If the roles of the $\mathrm{CN}$ and the $\mathrm{ABL}$ are as postulated by Killcross et al. (1997), lesions to the $\mathrm{CN}$ would be expected to block place aversions. This component of our task is most similar to the classical fear response. The differential fluid consumption seen in the conditional discrimination task may also be due to a direct context- $\mathrm{LiCl}$ association and the ability of the context (because of this association) to influence ongoing behavior (i.e., drinking). If this possibility is true, lesions of the ABL may affect the drinking aspect of the task. This account of occasion setting is similar to that put forth by Bombace et al. (1991), discussed in the introduction. This pattern of results is somewhat unlikely, given that rats with large lesions of the amygdala (including the ABL) could acquire the conditional discrimination task. However, lesioning the $\mathrm{ABL}$ alone will provide a more direct test of this hypothesis.

Rats with lesions to either the $\mathrm{CN}$ or the $\mathrm{ABL}$ of the amygdala were compared with sham-lesioned rats on the conditional discrimination task.

\section{Method}

Subjects. Thirty-seven adult male Wistar rats, weighing 350 $400 \mathrm{~g}$ at the beginning of behavioral training, were used as subjects. The rats were maintained as in the previous experiment.

Surgery. Ten rats underwent ibotenic acid lesions of the $\mathrm{CN}$ of the amygdala. The rats were anesthetized with sodium pentobarbital $(65 \mathrm{mg} / \mathrm{kg}$ i.p. $)$ and were placed in a stereotaxic instrument. After a scalp incision was made, holes were drilled in the skull to permit microinjections of the ibotenic acid. Using a 1.0- $\mu$ l Hamilton syringe mounted on the stereotaxic instrument, injections of $2 \%$ ibotenic acid were made at one site per hemisphere (AP - 2.0; $\mathrm{ML} \pm 4.1$; DV from skull surface -8.0 ) in a volume of $0.2 \mu \mathrm{l} /$ site. Ibotenic acid was injected at a rate of $0.05 \mu \mathrm{l} / \mathrm{min}$, and the needle was left in place for an additional $5 \mathrm{~min}$ following infusion. Ten sham-lesioned rats were treated in the same manner but were injected with sterile saline $(0.9 \% \mathrm{NaCl})$. Nine rats underwent ibotenic acid lesions of the $\mathrm{ABL}$. Injections of $2 \%$ ibotenic acid were made at one site per hemisphere (AP $-2.6 ; \mathrm{ML} \pm 5.0 ; \mathrm{DV}$ from skull surface -8.0$)$ in a volume of $0.3 \mu \mathrm{l} / \mathrm{site}$. Eight sham-lesioned rats were treated in the same manner but were injected with sterile saline $(0.9 \% \mathrm{NaCl})$.

Conditional discrimination training. After recovery from surgery, the four groups of rats were trained on the conditional discrimination task used in the previous experiment. On danger days, the rats were placed in a novel context $15 \mathrm{~min}$ prior to $15-\mathrm{min}$ access to a novel $0.1 \%$ saccharin solution. Removal of the saccharin solution was followed by an i.p. injection of $60 \mathrm{mg} / \mathrm{kg} \mathrm{LiCl} \mathrm{dis-}$ solved in $3 \mathrm{ml} / \mathrm{kg}$ physiological saline, and the rats were returned to the home cage. On safe days, the rats were placed in a second novel context $15 \mathrm{~min}$ prior to $15-\mathrm{min}$ access to the same saccharin solution. Saccharin removal was followed by an i.p. injection of physiological saline, and the rats were returned to the home cage. This phase of the experiment consisted of 17 cycles of alternating safe and danger days for both groups.

Vinegar transfer test. At the end of conditional discrimination training, all the rats were given a 2-day transfer test with a novel $2 \%$ vinegar solution. The rats were exposed to both training contexts, in a counterbalanced order, $15 \mathrm{~min}$ prior to 15 - $\mathrm{min}$ access to the vinegar solution. No injections were given after removal of the flavored solution.

Place aversion testing. The rats were given two place tests, one after Cycle 12 and one at the end of the acquisition phase (after the transfer test), to assess acquisition of a Pavlovian aversion to the context associated with $\mathrm{LiCl}$ injections. The test procedure consisted of placing a rat in a neutral gray zone between the black and the white contexts used during training. The amount of time spent in each of the two training contexts was recorded in seconds for a 10 -min period. Again, the presence of the neutral gray zone meant that time spent in the danger context was independent of time spent in the safe context.

\section{Results and Discussion}

Histology. Histological analysis of the brains of $\mathrm{CN}$ lesioned rats revealed that most of the damage from the ibotenic acid was restricted to the $\mathrm{CN}$, and in all cases, the majority of the $\mathrm{CN}$ was destroyed. Occasionally, there was some minor damage to other amygdala structures. One rat from the $\mathrm{CN}$ group was removed from the behavioral analysis because of ABL damage. Thus, behavioral data were analyzed for $9 \mathrm{CN}$-lesioned and 10 sham-lesioned rats. Schematic drawings of the largest and smallest $\mathrm{CN}$ lesions are shown in Figure 6A. In all the ABL-lesioned animals, the majority of the basal nu-
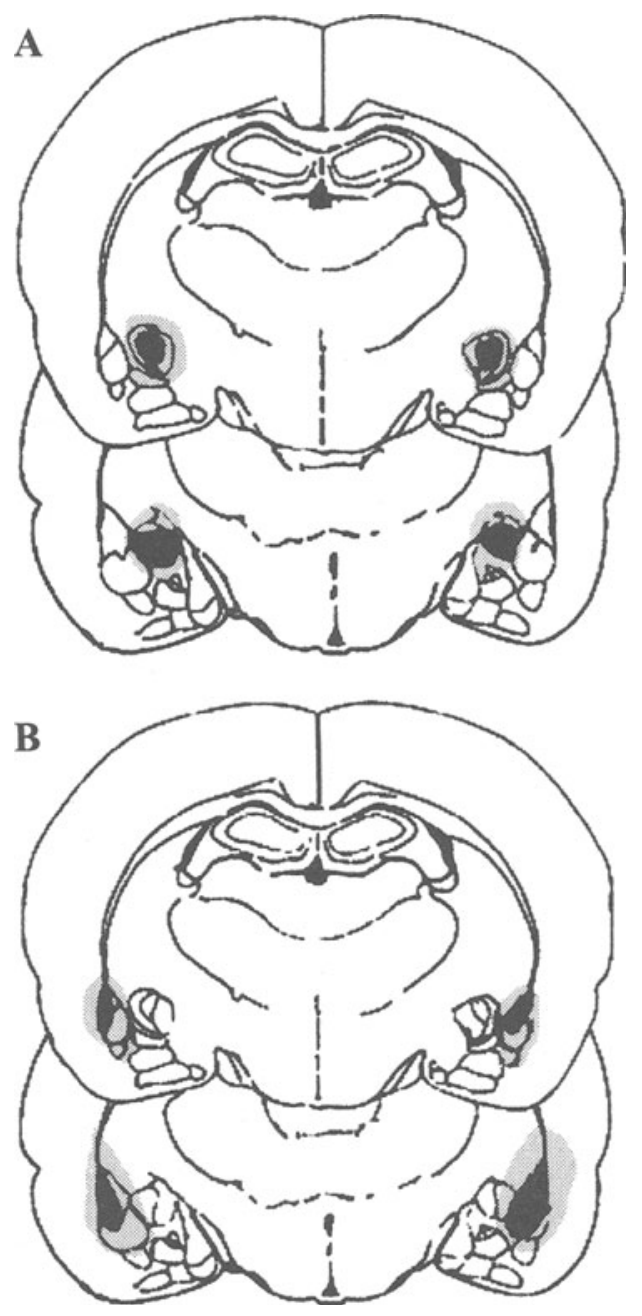

Figure 6. Schematic drawings of two coronal sections (AP from bregma -2.12 and 2.60) of the largest (gray) and smallest (black) central nucleus (panel $A$ ) and basolateral nucleus (panel B) lesions in rats from Experiment 2. From The Rat Brain in Stereotaxic Coordinates (Figures 26 and 28), by G. Paxinos and C. Watson, 1982, New York: Academic Press. Copyright 1982 by Academic Press. Adapted with permission. 
cleus, as well as the lateral nucleus, was destroyed. In some animals, damage was also evident in the ventral endopiriform nucleus and, occasionally, on the edge of the $\mathrm{CN}$. Two rats from the ABL group were removed from the behavioral analysis owing to damage to the $\mathrm{CN}$. Thus, behavioral data were analyzed for $7 \mathrm{ABL}-$ lesioned and 8 sham-lesioned rats. Schematic drawings of the largest and smallest ABL lesions are shown in Figure 6B.

Conditional discrimination training. Both $\mathrm{CN}$ - and sham-lesioned rats learned the conditional discrimination task, consuming less saccharin in the danger context than in the safe context (Figure 7A). A $2 \times 17 \times 2$ (groups $\times$ cycles $X$ days) ANOVA over the acquisition phase revealed a significant cycles $\times$ days interaction $[F(16,288)=12.0$, $p<.05]$, reflecting acquisition of the discrimination. The groups did not differ in acquisition, as was evidenced by the lack of a significant interaction of the group variable with any other variable. Furthermore, separate ANOVAs performed on the last cycle, the last three cycles, and the last five cycles failed to demonstrate a significant interaction of the group variable with any other variable.

Similarly, both the ABL- and the sham-lesioned rats learned the conditional discrimination task, consuming less saccharin in the danger context than in the safe con-
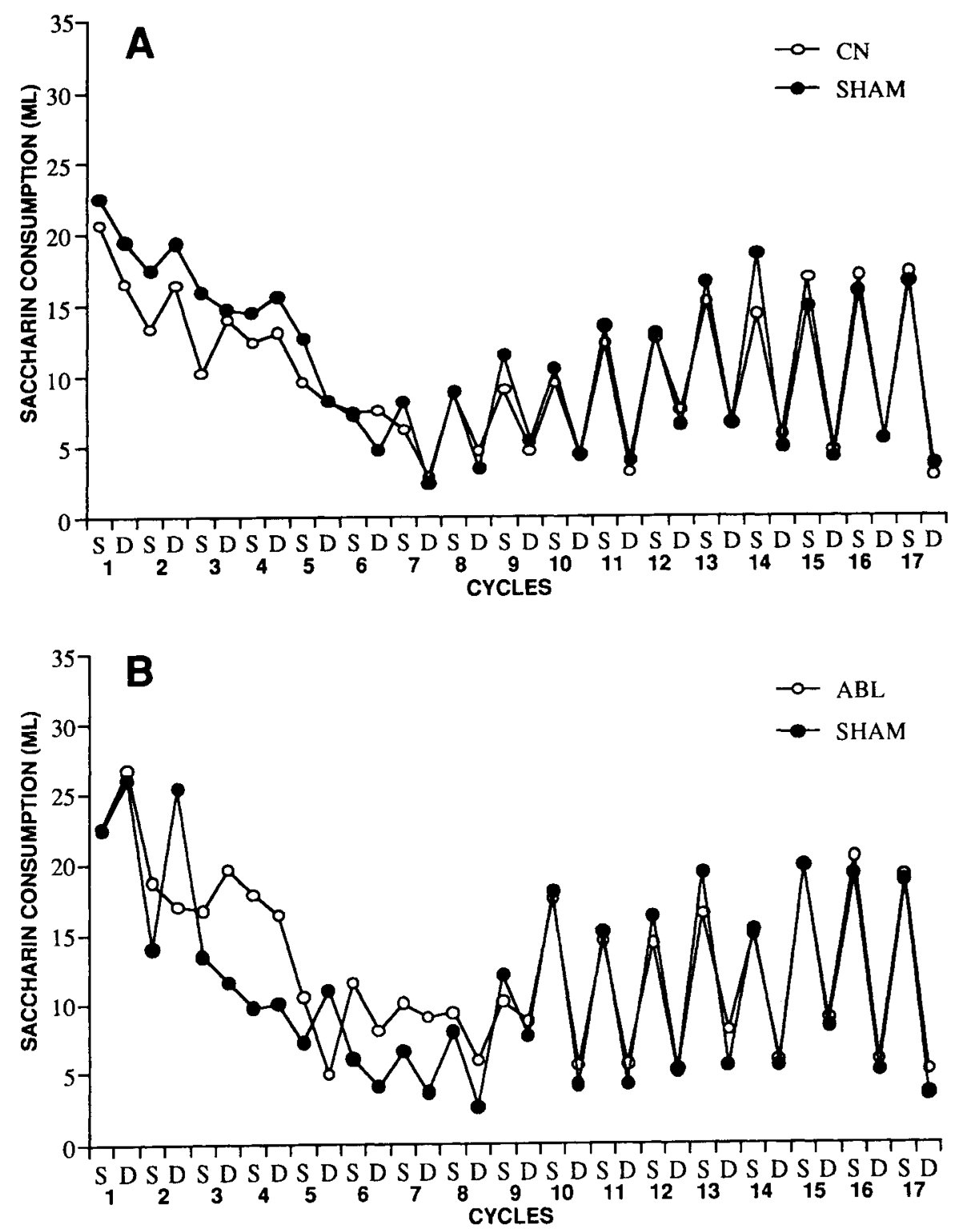

Figure 7. Saccharin consumption $(\mathrm{ml})$ by the sham- $(n=10)$ and central-nucleus- $(\mathrm{CN} ; n=9)$ lesioned groups (panel A) and by the sham- $(n=8)$ and basolateral-nucleus- $(\mathrm{ABL} ; n=7)$ lesioned groups (panel B) during the 17 cycles of conditional discrimination training in Experiment $2 . S$ = safe day trials where the rats receive Context 1 paired with saccharin-saline; $D=$ danger day trials where the rats received Context 2 paired with saccharin-LiCl. 
text (Figure 7B). A $2 \times 17 \times 2$ (groups $\times$ cycles $\times$ days) ANOVA over the acquisition phase revealed a significant groups $\times$ cycles $\times$ days interaction $[F(16,221)=2.04$, $p<.05$ ], reflecting the higher saccharin consumption of the lesioned rats early in training. However, separate ANOVAs performed on the last cycle, the last three cycles, the last five cycles, and the last seven cycles failed to demonstrate a significant interaction of the group variable with any other variable.

Vinegar transfer test. Both the $\mathrm{CN}$ - and the shamlesioned groups showed transfer of conditional control of fluid consumption to the novel flavor (Figure 8A). A $2 \times 2$ (groups $\times$ context) ANOVA revealed only a sig- nificant main effect of context $[F(1,17)=41.2, p<.05]$, confirming that both groups suppressed consumption of the vinegar solution in the danger context, relative to the safe context.

Similarly, both the ABL- and the sham-lesioned groups showed transfer of conditional control of fluid consumption to the novel flavor (Figure 8B). A $2 \times 2$ (groups $\times$ context) ANOVA revealed only a significant main effect of context $[F(1,13)=28.6, p<.05]$, confirming that the rats in both groups suppressed vinegar consumption in the danger context, relative to the safe context.

Since consumption of both saccharin and vinegar was comparable between the $\mathrm{CN}$ - and $\mathrm{ABL}$-lesioned rats and
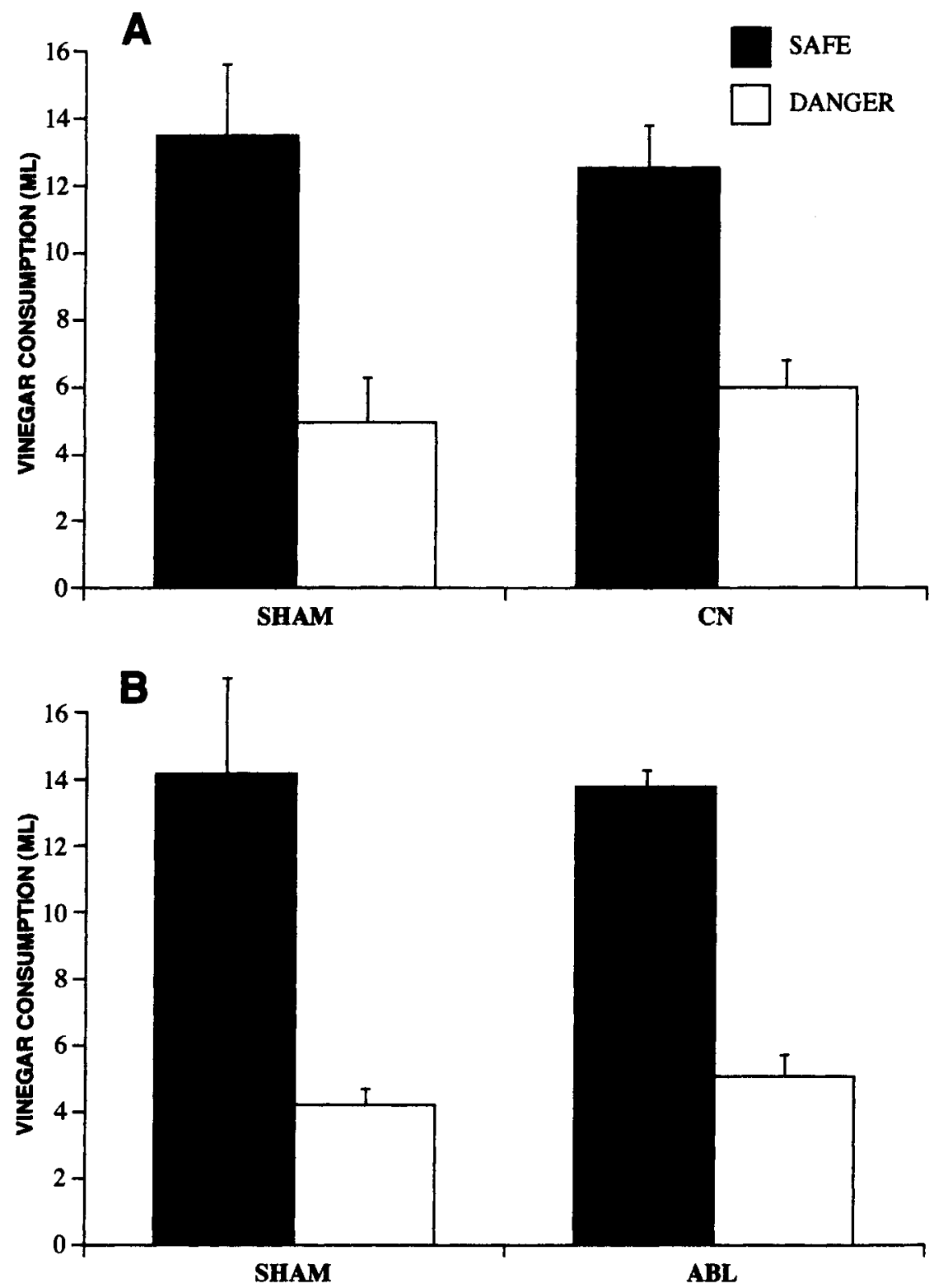

Figure 8. Means ( $\pm S E M)$ for vinegar consumption (in milliliters) by the sham- and centralnucleus- (CN) lesioned groups (panel $A$ ) and by the sham- and basolateral-nucleus- $(A B L)$ lesioned groups (panel B) in Experiment 2 during the 2-day transfer test. 

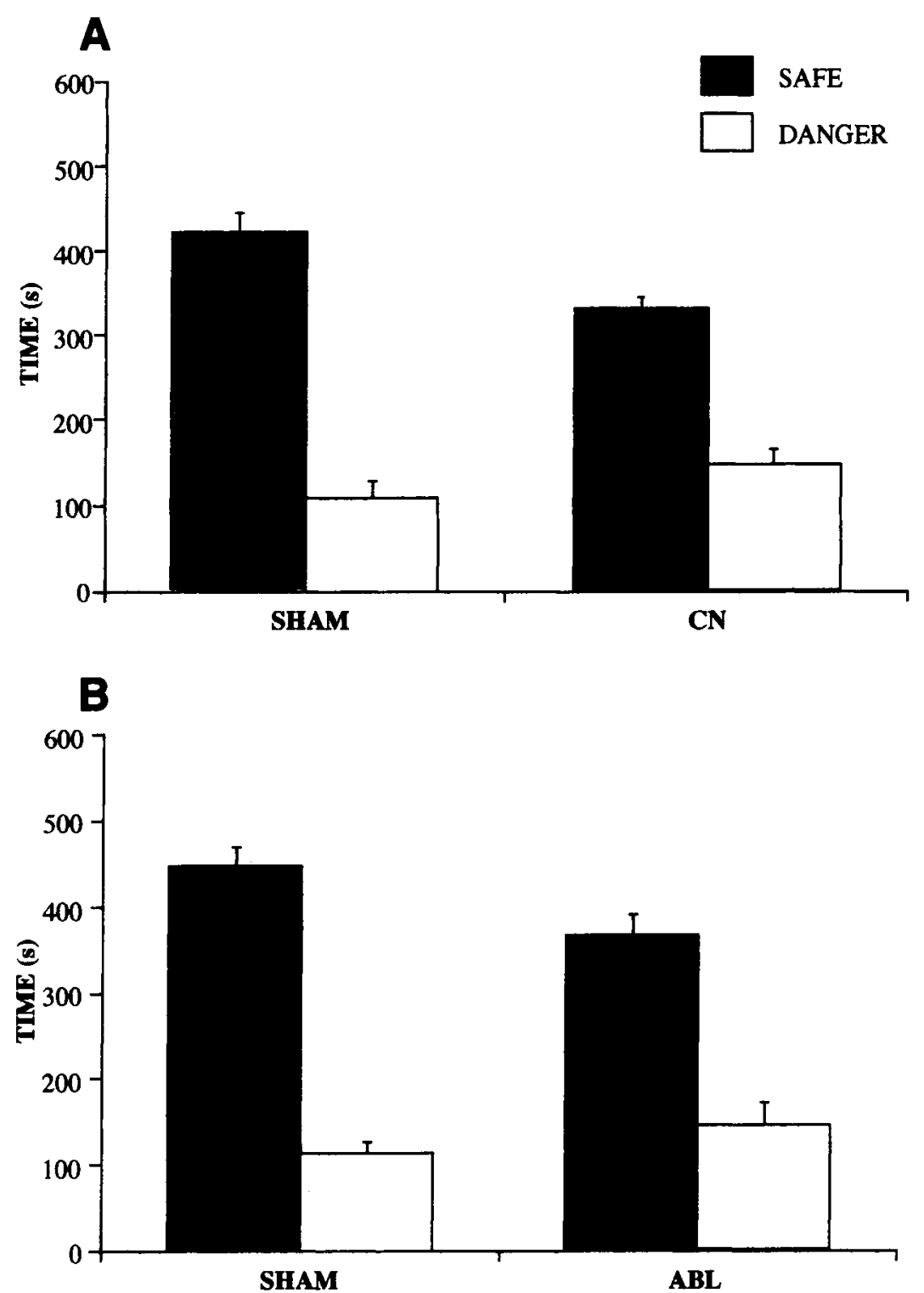

Figure 9. Means $( \pm S E M)$ for times (in seconds) spent in each of the two training contexts during the two 10-min place tests by the rats in the sham- and central-nucleus(CN) lesioned groups (panel $A$ ) and by the sham- and basolateral-nucleus-lesioned (ABL) groups (panel B) in Experiment 2. Since the two place tests were not statistically different, the data from the two tests have been combined. Safe $=$ the context associated with saline during training, and Danger = the context associated with $\mathrm{LiCl}$ during training.

their appropriate sham-lesioned controls, the performance of these rats on a direct CTA was not assessed.

Place aversions. The two place tests, given after $\mathrm{Cy}$ cle 12 and at the end of conditional discrimination training, revealed that both the $\mathrm{CN}$ - and the sham-lesioned groups avoided the context associated with $\mathrm{LiCl}$ (Figure 9A). A $2 \times 2 \times 2$ (groups [CN or sham] $\times$ test [1 or 2 ] $\times$ context [safe or danger]) ANOVA revealed a significant main effect of group $[F(1,34)=5.9, p<.05]$, a significant main effect of context $[F(1,34)=165.2, p<.05]$, confirming that both groups showed a place aversion, and a significant groups $\times$ context interaction $[F(1,34)=10.5$, $p<.05]$, demonstrating that the place aversion was bigger in the sham-lesioned rats. Since there was no main effect of test and no interaction of the test variable with any other variable, data from the two place tests have been combined in Figure 9A. Thus, although the direct association between the context and $\mathrm{LiCl}$ was partially blocked, lesioned animals were not statistically different from sham-lesioned controls on the conditional discrimination.

Similar results were obtained in the sham and ABL groups (Figure 9B). A $2 \times 2 \times 2$ (groups [ABL or sham] 
$\times$ test [ 1 or 2] $\times$ context [safe or danger] ) ANOVA revealed a significant main effect of group $[F(1,26)=16.3$, $p<.05]$, a significant main effect of context $[F(1,26)=$ $131.9, p<.05]$, confirming that both groups showed a place aversion, and a significant groups $\times$ context interaction $[F(1,26)=5.3, p<.05]$, demonstrating that the place aversion was bigger in the sham-lesioned rats. Since there was no main effect of test and no interaction of the test variable with any other variable, data from the two place tests have been combined in Figure 9B. Once again, we see that although the direct association between the context and $\mathrm{LiCl}$ was partially blocked, lesioned animals were not statistically different from sham-lesioned controls on the conditional discrimination.

\section{GENERAL DISCUSSION}

Data from the sham-lesioned rats trained on the conditional discrimination task showed that contextual cues could serve as occasion setters to modulate a taste aversion and that this occasion-setting function transfers to a novel flavor. Furthermore, sham-lesioned Pavlovian control groups (Experiment 1) did not suppress fluid consumption in a context directly associated with $\mathrm{LiCl}$. These data suggest that a direct association between context and $\mathrm{LiCl}$ is not sufficient for discriminative or differential fluid consumption. This behavioral dissociation between simple excitation and occasion setting has also been demonstrated in other laboratories (Bouton \& Swartzentruber, 1986; Holland, 1989, 1991; Rescorla, 1991).

Data from amygdala-lesioned rats in the present study provide further neuroanatomical support for the dissociation of conditional discrimination learning and simple excitatory conditioning. Rats with large lesions of the amygdala acquired the conditional discrimination task with contextual cues but did not show a simple Pavlovian aversion, as measured by the place choice test. Rats with lesions restricted to either the $\mathrm{CN}$ or the $\mathrm{ABL}$ were no different than control rats on the conditional discrimination task but showed a partial block of the context- $-\mathrm{LiCl}$ direct association, as measured in the place choice test. Thus, the aversive properties of the context, as acquired through Pavlovian conditioning, are not necessary for conditional discrimination learning. The large amygdala lesions (Experiment 1) produced a severe impairment on the place aversion (the Pavlovian task) and a smaller deficit on the conditional discrimination task. The smaller lesions (Experiment 2) produced no deficit on the conditional discrimination task but did attenuate the place aversion. Thus, the discrete lesions had smaller effects on both tasks, and this pattern of results could be taken to suggest that the two tasks have a similar underlying mechanism. Although we admit that this is a possible interpretation, one finding from Experiment 1 seems to argue against this possibility. The use of multiple place tests throughout acquisition of the conditional discrimination in that experiment revealed that the context aversion was acquired faster than the conditional control over fluid consumption in shamlesioned animals. Since the conditional discrimination is acquired more slowly, we suggest that this task is the more difficult and, as such, should be more susceptible to disruption. The Pavlovian component (the place aversion) is acquired more quickly, and yet, this is the task most easily disrupted. The most convincing argument for conditional discrimination learning and Pavlovian conditioning's having separate underlying mechanisms would be a double dissociation. However, since amygdala lesions disrupt the task that is most easy to learn, the single dissociation presented here suggests that the difference in performance of amygdala-lesioned rats on the conditional discrimination task and the place aversion reflects a qualitative rather than a quantitative difference. Although the results from amygdala lesioned rats in the present study support the previous behavioral dissociation between conditional discrimination learning and Pavlovian conditioning, we acknowledge that this result may be task specific and that it may not be possible to generalize to other occasion setting tasks that use different reinforcers and modality of cues.

Although amygdala-lesioned rats (Experiment 1) did acquire the conditional discrimination task, consuming significantly less saccharin in the danger context than in the safe context, the magnitude of difference between consumption in the safe and in the danger contexts was smaller than that for sham-lesioned controls. Given that the amygdala-lesioned rats trained on the Pavlovian control task also consumed less saccharin than did shamlesioned controls in the home cage, the effect of the lesions is probably not on occasion setting. We argue that the deficit is a nonassociative effect of $\mathrm{LiCl}$ exposure that develops with repeated injections, since the effect is seen in Pavlovian control rats as well. The deficit in amygdalalesioned rats is only seen in a situation in which shamlesioned rats consume high volumes of fluid; the groups did not differ on the vinegar transfer test. It may be possible to get around the difference between the sham- and amygdala-lesioned rats on fluid consumption by doing occasion setting with a procedure that does not require rats to make a drinking response, such as the taste reactivity paradigm (Spector, Breslin, \& Grill, 1988), or by using a flavor, such as vinegar, that is not consumed in high volumes. Nevertheless, the dissociation between conditional discrimination learning and simple Pavlovian learning seen after amygdala lesions is not due to the fact that a taste response was employed in occasion setting versus a choice response in the place test. Impairments are seen after amygdala lesions in simple Pavlovian conditioning both when contexts (conditioned place aversion) and when tastes (conditioned taste aversion) are employed as CSs, although the deficit in taste aversion learning is less severe than the deficit in place aversion learning. The anatomical locus for this deficit must lie outside the $\mathrm{CN}$ and the $\mathrm{ABL}$, since these lesions (Experiment 2) had no significant effect on the level of fluid consumption. Given that the large lesions also included damage to the medial amygdala, which has been implicated in other taste paradigms, particularly salt intake (Nitabach, Schulkin, \& Epstein, 1989), it is possible that the deficit in saccharin intake seen in Experiment 1 was due to damage to this area. 
Those rats with large amygdala lesions (Experiment 1) that were trained on the Pavlovian task never showed an aversion to the context directly associated with $\mathrm{LiCl}$, even after 18 pairings of the context and $\mathrm{LiCl}$. In addition, those rats trained on the conditional discrimination task never showed a significant aversion to the danger context, which is typical in normal rats. However, animals with discrete lesions to either the $\mathrm{CN}$ or the ABL showed only a partial block of the Pavlovian aversive properties of the contextual cues. Thus, the effects of the large lesions may reflect the summation of the contribution from these two structures and, thus, offer support to a parallelprocessing view of amygdala function. However, since our large lesions damaged more than the $\mathrm{CN}$ and the ABL, further studies are needed to test this possibility. To fully explore this idea, it will be necessary to do combined lesions of the $\mathrm{CN}$ and the ABL (not of the entire amygdala) and to look at performance on the conditional discrimination task. One may conclude that, since both $\mathrm{CN}$ and $\mathrm{ABL}$ lesions had the same behavioral effect, the data support a serial-processing view of amygdala function. This may be possible if lesions of the two nuclei were only partial lesions, but it appears that the majority of the $\mathrm{CN}$ and the ABL were destroyed by our lesions. However, we would not completely rule out the serial-processing view, because the necessary areas for correct processing of our paradigm may be larger than the anatomically defined $\mathrm{ABL}$ or $\mathrm{CN}$. The present data do not support either the strict parallel- or the strict serial-processing views of amygdala function. If information is processed in parallel, neither lesion alone should produce a deficit in place aversion learning. Conversely, if information is processed serially, then either lesion alone should produce the full impairment. Since both $\mathrm{CN}$ and ABL lesions produced a partial effect on place learning, a third hypothesis remains viable. This processing view is one in which the subnuclei of the amygdala actually interact synergistically in order to acquire simple place learning. If this were the case, by lesioning each of the subnuclei, we may have uncovered partial effects, as was demonstrated by both lesions in this study.

Although occasion setting and simple conditioning are thought to be independent, the context- $\mathrm{LiCl}$ direct association could contribute to occasion setting, and since rats with large amygdala lesions (Experiment 1 ) are impaired on this form of simple conditioning, they also show deficits on the conditional task. There are several possible ways for a context- $\mathrm{LiCl}$ association to influence performance on the conditional discrimination task. In a conditional discrimination paradigm similar to the one used in the present study, where contextual cues were trained to modulate fluid consumption (Puente, Cannon, Best, \& Carrell, 1988), prior context- $\mathrm{LiCl}$ pairings were found to enhance the development of contextual control of fluid consumption when subsequent conditional discrimination training began. The authors argued that this enhancement was due to summation of the excitatory conditioning to the context with its occasion-setting function. In Experiment 1, then, the performance of the S-DIS rats (who acquired a Pavlovian aversion to the context) may be seen as enhanced, relative to the A-DIS rats (who did not show a Pavlovian aversion to the context). Similarly, Rescorla (1991) found that separate excitatory conditioning of an occasion setter enhanced both facilitation and inhibition (positive and negative occasion setting, respectively), suggesting that separate excitatory training enhanced the processing of the conditional cue. Since an association between the context and $\mathrm{LiCl}$ develops before conditional discrimination learning in sham-lesioned animals, this may result in enhanced processing of the contextual cues. This enhanced processing may result in better performance on the conditional discrimination task, relative to amygdala-lesioned rats, who did not develop this Pavlovian association and, presumably, would not have this enhanced processing. Finally, conditioned fear to the context may serve to potentiate the response (avoidance) to the fluid in a manner suggested by Wagner and colleagues (Bombace et al., 1991). However, since the amygdala-lesioned rats trained on the Pavlovian control task also consumed less saccharin than did the sham controls in the home cage, the most parsimonious explanation for the lower saccharin consumption on safe trials may be the nonassociative effect of $\mathrm{LiCl}$ exposure, as was elaborated earlier. Indeed, the contribution of a context- $\mathrm{LiCl}$ direct association is probably small in this type of learning, since the rats with discrete lesions of either the $\mathrm{CN}$ or the $\mathrm{ABL}$ were no different than sham-lesioned controls on the conditional discrimination task but still showed deficits on the place aversion component. As such, the present data would seem to support Holland's (1989) view of occasion setting, where conditional control over responding is independent of a direct association between the occasion setter and the US.

The evidence that lesioned rats could acquire a more complex form of learning but were impaired in learning a simple Pavlovian association seems counterintuitive. However, similar results have been reported in humans (Bechara et al., 1995; LaBar, LeDoux, Spencer, \& Phelps, 1995) and rats (McDonald \& White, 1993). In the human studies, conditioned autonomic fear responses were impaired in subjects with damage to the amygdala. These same subjects, however, were able to declare the contingencies that were currently active (Bechara et al., 1995). McDonald and White showed that rats with amygdala damage could learn a spatial version of the win-shift task in a radial-arm maze. Amygdala-lesioned rats could not learn the intuitively simpler task of approaching a single visual cue that had previously been paired with a reward. In essence, these amygdala-lesioned rats could learn about a configuration of cues but not that a single element predicted food. Data such as these (presence of more complex learning in the absence of simple learning) are probably the best support for the idea that the mammalian brain has multiple memory systems. It has previously been suggested that the occasion-setting function of a stimulus is fundamentally different than its simple Pavlovian properties (Holland, 1991; Rescorla, 1991; Skinner, Martin, Harley, et al., 1994; Skinner, Martin, Pridgar, 
\& van der Kooy, 1994). Our previous behavioral studies showed that simple direct associations were not sufficient to produce conditional discriminative performance (Skinner, Martin, Harley, et al., 1994; Skinner, Martin, Pridgar, $\&$ van der Kooy, 1994). The present anatomical data support our previous behavioral dissociation and suggest that simple, Pavlovian associations are not necessary for conditional discrimination learning using contextual cues.

\section{REFERENCES}

Bechara, A., Tranel, D., Damasio, H., Adolphs, R., Rockland, C., \& Damasio, A. R. (1995). Double dissociation of conditioning and declarative knowledge relative to the amygdala and hippocampus in humans. Science, 269, 1115-1118.

BEChaRA, A., \& VAN DER KOOY, D. (1992). A single brain stem substrate mediates the motivational effects of both opiates and food in nondeprived rats but not in deprived rats. Behavioral Neuroscience, 106, 351-363.

Best, M. R., Brown, E. R., \& Sowell, M. K. (1984). Taste-mediated potentiation of noningestional stimuli in rats. Learning \& Motivation, 15, 244-258.

Bombace, J. C., Brandon, S. E., \& Wagner, A. R. (1991). Modulation of a conditioned eyeblink response via a putative emotive stimulus conditioned with hindleg shock. Journal of Experimental Psychology: Animal Behavior Processes, 17, 323-333.

Bouton, M. E., \& SWARTZEnTruber. D. (1986). Analysis of the associative and occasion-setting properties of contexts participating in a Pavlovian discrimination. Journal of Experimental Psychology: Animal Behavior Processes, 12, 333-350.

Brown, E. E., \& Fibiger, H. C. (1993). Differential effects of excitotoxic lesions of the amygdala on cocaine-induced conditioned locomotion and conditioned place preference. Psychopharmacology, 113, 123-130.

Davis, M. (1992). The role of the amygdala in fear and anxiety. Annual Review of Neurosciences, 15, 353-375.

Dunn, L. T., \& EveritT, B. J. (1988). Double dissociation of the effects of amygdala and insular cortex lesions on conditioned taste aversion, passive avoidance, and neophobia in the rat using the excitotoxin ibotenic acid. Behavioral Neuroscience, 102, 3-23.

FANSELOW, M. S., \& KiM, J. J. (1994). Acquisition of contextual fear conditioning is blocked by application of an NMDA receptor antag. onist D,L-2-amino-5-phosponovaleric acid into the basolateral amygdala. Behavioral Neuroscience, 108, 210-212.

Gallo, M., Roldan, G., \& Bures, J. (1992). Differential involvement of gustatory insular cortex and amygdala in the acquisition and retrieval of conditioned taste aversion in rats. Behavioral Brain Research, 52, 91-97.

GASTON, K. E. (1978). Brain mechanisms of conditioned taste aversion learning: A review of the literature. Physiological Psychology, 6 , 340-353.

Holland, P. C. (1989). Acquisition and transfer of conditional discrimination performance. Journal of Experimental Psychology: Animal Behavior Processes, 15, 154-165.

Holland, P. C. (1991). Acquisition and transfer of occasion setting in operant feature positive and feature negative discriminations. Learning \& Motivation, 22, 366-387.

Holland, P. C. (1995). Transfer of occasion setting across stimulus and response in operant feature positive discriminations. Learning \& Motivation, 26, 239-263.

Kesner, R. P., Berman R. F., Burton, B., \& Hankins, W. G. (1975).
Effects of electrical stimulation of amygdala upon neophobia and taste aversion. Behavioral Biology, 13, 349-358.

KESNER, R. P., BERMAN, R. F., \& TARDiF, R. (1992). Place and taste aversion learning: Role of basal forebrain, parietal cortex, and amygdala. Brain Research Bulletin, 29, 345-353.

Killcross, S., Robiins, T. W., \& Everitt, B. J. (1997). Different types of fear-conditioned behavior mediated by separate nuclei within amygdala. Nature, 388, 377-380.

LaBar, K. S., LeDoux, J. E., Spencer, D. D., \& Phelps, E. A. (1995). Impaired fear conditioning following unilateral temporal lobectomy in humans. Journal of Neuroscience, 15, 6846-6855.

LeDoux, J. E. (1993). Emotional memory systems in the brain. Behavioral Brain Research, 58, 69-79.

LeDoux, J. E., Cicchetti, P., Xagoraris, A., \& Romanski, L. M. (1990). The lateral amygdaloid nucleus: Sensory interface of the amygdala in fear conditioning. Journal of Neuroscience, 10, 1062-1069.

MCDONALD, R. J., \& WhiTE, N. M. (1993). A triple dissociation of memory systems: Hippocampus, amygdala, and dorsal striatum. Behavioral Neuroscience, 107, 3-22.

Mucha, R. F., van der Kooy, D., O'Shaughnessy, M., \& BuceNIEKS, P. (1982). Drug reinforcement studied by the use of place conditioning in rat. Brain Research, 243, 91-105.

Nader, K., \& LeDoux, J. E. (1997). Is it time to invoke multiple fear learning systems in the amygdala? Trends in Cognitive Sciences, 1 , 241-244.

Nitabach, M. N., Schulkin, J., \& Epstein, A. N. (1989). The medial amygdala is part of a mineralocorticoid-sensitive circuit controlling $\mathrm{NaCl}$ intake in the rat. Behavioural Brain Research, 35, 127-143.

PAXINos, G., \& WATSON, C. (1982). The rat brain in stereotaxic coordinates. New York: Academic Press.

Phillips, R. G., \& LeDoux, J. E. (1992). Differential contribution of amygdala and hippocampus to cued and contextual fear conditioning. Behavioral Neuroscience, 106, 274-285.

Puente, G. P., Cannon, D. S.. Best, M. R., \& Carrell, L. E. (1988). Occasion setting of fluid ingestion by contextual cues. Learning \& Motivation, 19, 239-253.

Rescorla, R. A. (1991). Separate reinforcement can enhance the effectiveness of modulators. Journal of Experimental Psychology: Animal Behavior Processes, 17, 259-269.

Skinner, D. M., Martin, G. M., Harley, C., Kolb, B., Pridgar, A., Bechara, A., \& VAN DER KoOY, D. (1994). Acquisition of conditional discriminations in hippocampal lesioned and decorticated rats: Evidence for learning that is separate from both simple classical conditioning and configural learning. Behavioral Neuroscience, 108. 911-926.

Skinner, D. M., Martin, G. M., Howe, R. D., Pridgar, A., \& van der KooY, D. ( 1995). Drug discrimination learning using a taste aversion paradigm: An assessment of the role of safety cues. Learning \& $\mathrm{Mo}$ tivation, 26, 343-369.

Skinner, D. M., Martin, G. M., Pridgar, A., \& van der Kooy, D. (1994). Conditional control of fluid consumption in an occasion setting paradigm is independent of Pavlovian associations. Learning \& Motivation, 25, 368-400.

Spector, A. C., Breslin, P., \& Grill, H. J. (1988). Taste reactivity as a dependent measure of the rapid acquisition of conditioned taste aversion: A tool for the neural analysis of taste-visceral associations. Behavioral Neuroscience, 102, 942-952.

WhIt LOW, J. W., JR., \& WAGNER, A. R. (1972). Negative patterning in classical conditioning: Summation of response tendencies to isolable and configural components. Psychonomic Science, 27, 299-301.

(Manuscript received August 4, 1999 ; accepted for publication October 14, 1999.) 